\title{
EFEITO DA ADIÇÃO DE ZEÓLITA E VERMICULITA NA LIXIVIAÇÃO DE POTÁSSIO DO SOLO
}

\author{
Luis Fernando WU \\ Mirian Chieko SHINZATO \\ Sandra ANDRADE \\ José Guilherme FRANCHI \\ Vanessa da Silva ANDRADE
}

\begin{abstract}
RESUMO
Este trabalho teve o objetivo de estudar a lixiviação do potássio $\left(\mathrm{K}^{+}\right)$adicionado em um solo (Latossolo Vermelho) e avaliar a eficiência de retenção desse íon com a adição de minerais com elevada capacidade de troca catiônica (CTC), como vermiculita e zeólita. Amostras de Latossolo Vermelho coletadas em Araraquara (SP) foram caracterizadas física, química e mineralogicamente. O solo possui textura argilosa, baixa acidez e é pobre em nutrientes e em minerais fontes de $\mathrm{K}^{+}$. A lixiviação de potássio nesse solo foi avaliada a partir de dois testes: (1) lixiviação de $\mathrm{K}^{+}$em colunas preenchidas com solos, na presença de vermiculita ou zeólita e (2) incubação de solos com vermiculita e zeólita durante 30 dias para verificar a interação desses minerais com o $\mathrm{K}^{+}$adicionado ao meio, na presença/ausência de $\mathrm{Ca}^{2+}$ (na forma de $\mathrm{CaCO}_{3}$ ). Os testes de lixiviação em colunas revelaram que a textura e a mineralogia do solo desempenham importante papel na retenção de $\mathrm{K}^{+}$, promovendo a rápida transferência de sua fase solúvel para a fase trocável. O latossolo perdeu, em média, somente $2 \%$ do total de $\mathrm{K}^{+}$adicionado ao sistema e esse valor decresce para 1,6\% na presença de vermiculita e 1,2\% com zeólita. Nos testes de incubação também se observou que o $\mathrm{K}^{+}$solúvel introduzido no meio é logo transferido para a fase trocável e a introdução de vermiculita e zeólita aumenta a taxa de sua retenção no solo. A presença de cálcio no meio, no entanto, não favorece a retenção de $\mathrm{K}^{+}$pela vermiculita - que prefere reter cátions de maior valência como o $\mathrm{Ca}^{2+}$. O mesmo não acontece com a zeólita, cujos sítios de troca preferem cátions de menor valência como o $\mathrm{K}^{+}$. De forma geral, verificou-se que a adição de minerais com elevada CTC aumenta a disponibilidade de $\mathrm{K}^{+}$na fase fixa, que pode servir de reserva desse íon, e ainda diminui a perda por lixiviação desse nutriente no solo.
\end{abstract}

Palavras-chave: potássio, lixiviação, Latossolo Vermelho, zeólita, vermiculita.

\section{ABSTRACT}

This study aimed to investigate the leaching of potassium $\left(\mathrm{K}^{+}\right)$from the soil (Oxisol) and to evaluate the efficiency of uptake of this ion with the addition of minerals with high cation exchange capacity (CEC), such as vermiculite and zeolite. Oxisol samples collected in Araraquara (SP) were physically, chemically and mineralogically characterized. The leaching of potassium from the soil was performed using two tests: (1) $\mathrm{K}^{+}$leaching using columns filled with soil, in the presence of vermiculite or zeolite, and (2) incubating soils with vermiculite and zeolite for 30 days to analyze the interaction between these minerals and the $\mathrm{K}^{+}$added to the soil in the presence/ absence of $\mathrm{Ca}^{2+}\left(\right.$ as $\left.\mathrm{CaCO}_{3}\right)$. The soil has clay texture and low acidity, and is poor in nutrients and mineral sources of $\mathrm{K}^{+}$. Tests in soil columns proved that the texture and mineralogy of the soil play an important role in the retention of $\mathrm{K}^{+}$, promoting its rapid transfer from the soluble to the exchangeable phase. The Oxisol released, on average, only $2 \%$ of the $\mathrm{K}^{+}$added to the soil, and this value decreased to $1.6 \%$ in the presence of vermiculite and to $1.2 \%$ in the presence of zeolite. In the incubation test, it was also 
noted that the $\mathrm{K}^{+}$added to the soil is rapidly transferred to the exchangeable phase, and that the retention rate of this cation increases in the soil in the presence of vermiculite and zeolite. However, the presence of calcium in the soil does not favor the retention of $\mathrm{K}^{+}$by vermiculite - which retains preferably cations of higher valence, such as $\mathrm{Ca}^{2+}$. The same is not true for zeolite, since its exchange sites hold preferably lower valence cations, such as $\mathrm{K}^{+}$. In general, it was found that the addition of minerals with high CEC increases the amount of $\mathrm{K}^{+}$in the fixed phase, which can serve as a reserve of this ion, and decreases the loss by leaching of this nutrient from the soil.

Keywords: potassium leaching, Oxisol, zeolite, vermiculite.

\section{INTRODUÇÃO}

O potássio, além do nitrogênio e fósforo, é considerado um dos nutrientes mais importantes para a fertilidade do solo. Apesar de ser um dos dez elementos mais abundantes da crosta terrestre (SKINNER 1996), o intenso processo de intemperismo químico em regiões de clima tropical não favorece o suprimento necessário desse nutriente no solo agrícola, por acelerar a sua lixiviação (BOHN et al. 2001). O Brasil, tendo a agricultura como um dos principais pilares de sua economia, tornou-se o quarto maior consumidor de fertilizantes no mundo atrás somente da China, EUA e Índia; mais especificamente, no caso do potássio, sua posição sobe para o terceiro lugar (ANDA 2010).

Os principais minerais de $\mathrm{K}^{+}$de interesse econômico são a silvita $(\mathrm{KCl})$ e a carnalita $\left(\mathrm{K}_{2} \mathrm{MgCa}_{2}\left(\mathrm{SO}_{4}\right)_{4} \cdot 2 \mathrm{H}_{2} \mathrm{O}\right)$, devido à sua elevada solubilidade e concentração; outros menos explorados são os sulfatos langbeinita $\left(\mathrm{KMg}_{2}\left(\mathrm{SO}_{4}\right)_{3}\right)$, polihalita $\left(\mathrm{K}_{2} \mathrm{MgCa}_{2}\left(\mathrm{SO}_{4}\right)_{4} \cdot 2 \mathrm{H}_{2} \mathrm{O}\right)$ e cainita $\left(\mathrm{MgSO}_{4} \mathrm{KCl}_{3} 3 \mathrm{H}_{2} \mathrm{O}\right)$, que apesar de possuírem potássio em sua composição, são insolúveis (NASCIMENTO \& LOUREIRO 2004).

O potássio, por ser um íon muito móvel, pode ser facilmente lixiviado (ALFARO et al. 2004) e essa perda pode aumentar dependendo da textura do solo, como nos arenosos (MALAVOLTA 1985).

Apesar do potássio fornecido pelos fertilizantes ser submetido a uma intensa lixiviação, ele pode ser fixado por sítios de troca disponíveis nos minerais do solo (BOYER 1991). Portanto, o conhecimento das formas de retenção desse nutriente no solo pode otimizar as condições de aplicação desse insumo, minimizando suas perdas (RAIJ et al. 2001).

A forma e a disponibilidade do potássio no solo dependem de vários fatores, mas principalmente dos minerais primários e secundários presentes, além da ciclagem desse nutriente pelas próprias plantas (WERLE et al. 2008), uma vez que a matéria orgânica também é considerada uma importante fonte de potássio no solo (KIEHL 1981).

Na prática, esse nutriente pode ser encontrado sob quatro formas (SPARKS 1987): (1) em solução, (2) na fase trocável, (3) na fase fixa e (4) em estruturas minerais. Todas essas formas, por sua vez, encontram-se em equilíbrio dinâmico (JALALI 2006).

Geralmente a fração solúvel encontra-se em pequenas concentrações no solo, quando comparada às demais formas, as quais constituem uma reserva que pode ficar por mais tempo disponível às plantas (WERLE et al. 2008). Depois da forma solúvel, o potássio disponível na fase trocável é o mais acessível para as plantas, uma vez que se encontra retido pelas cargas negativas da matéria orgânica e partículas da fração argila. $\mathrm{O} \mathrm{K}^{+}$da fase fixa, por sua vez, é considerado uma importante reserva encontrada em certos filossilicatos e tectossilicatos. Finalmente, o $\mathrm{K}^{+}$das estruturas minerais, como dos feldspatos, é liberado lentamente, à medida que sofrem intemperismo químico (SHARPLEY 1989) e formam minerais secundários como a caulinita $\left(\mathrm{Si}_{2} \mathrm{Al}_{2} \mathrm{O}_{5}(\mathrm{OH})_{4}\right)$, argilomineral $(1: 1)$ associado a solos mais intemperizados, que não apresenta elevada CTC, ao contrário das argilas expansivas (tipo 2:1), como as vermiculitas e esmectitas.

Em solos de baixa CTC a retenção dos cátions trocáveis depende de uma série denominada liotrófica, onde a energia de ligação com os colóides do solo aumenta para íons com maior valência, menor raio iônico, maior grau de hidratação e maior concentração na solução do solo. Em geral, assume-se que os colóides tem maior preferência por $\mathrm{H}^{+}, \mathrm{Al}^{3+}, \mathrm{Ca}^{2+} \mathrm{e} \mathrm{Mg}^{2+}$, em detrimento ao $\mathrm{K}^{+}$, resultando na sua maior lixiviação (RAIJ 1991). Por isso, a retenção do potássio nas fases trocáveis e fixas dos solos pode ser comprometida pelo alumínio (comumente presente em solos tropicais), assim como pelo cálcio (adicionado como corretivos de solos ácidos), entre outros íons. 
O objetivo do trabalho consistiu em analisar, em escala laboratorial, a taxa de lixiviação de potássio adicionado a um solo tropical e o efeito da presença de vermiculita e zeólita na retenção desse nutriente.

\section{MATERIAIS E MÉTODOS}

Com a finalidade de verificar a contribuição da fase fixa na retenção de $\mathrm{K}^{+}$analisou-se a adição de vermiculita e de zeólita naturais num solo típico e abundante em áreas tropicais, o Latossolo Vermelho. Esses materiais foram inicialmente caracterizados e, em seguida, utilizados nos testes de lixiviação experimental.

\subsection{Caracterização do solo}

O Latossolo Vermelho utilizado nesse estudo foi coletado no Município de Araraquara (SP), na camada entre 0-20 $\mathrm{cm}$ de profundidade. Os procedimentos para a coleta seguiram as normas estabelecidas pelo Instituto Agronômico de Campinas (CAMARGO et al. 2009). Após secagem à temperatura ambiente, a amostra de solo foi quarteada e peneirada (malha $2 \mathrm{~mm}$ ) e, em seguida, caracterizada por meio das seguintes análises:

- Mineralógica: os ensaios de difração de raios $\mathrm{X}$ foram realizados no Laboratório de Difração de raios X do Instituto de Geociências da USP em amostras na forma de pó (porta amostra de lâmina de vidro) em equipamento da Siemens (D5000), operando com radiação $\mathrm{CuK} \alpha, 2 \theta$ variando de 3 a $65^{\circ} \mathrm{com}$ passo de $0,050^{\circ}$ e tempo de contagem de $0,5 \mathrm{~s} /$ passo.

- Química: fluorescência de raios X (Axios Advanced/PANalytical) do Laboratório de Caracterização Tecnológica da Escola Politécnica da Universidade de São Paulo (USP).

- Granulométrica: método do densímetro (Laboratório de Física do Solo do Centro de Pesquisa e Desenvolvimento de Solos e Recursos Ambientais do Instituto Agronômico de Campinas - IAC).

- Fertilidade: os teores dos principais macronutrientes como fósforo $(\mathrm{P})$, potássio $(\mathrm{K})$, cálcio (Ca) e magnésio $(\mathrm{Mg})$ foram determinados após extração com resina, respectivamente, por técnicas de colorimetria $(\mathrm{P})$, fotometria de chama $(\mathrm{K})$ e espectrofotometria de absorção atômica $(\mathrm{Ca}$ e $\mathrm{Mg})$. Os micronutrientes cobre $(\mathrm{Cu})$, ferro $(\mathrm{Fe})$, manganês $(\mathrm{Mn})$ e zinco $(\mathrm{Zn})$ foram extraídos com solução de DTPA e o boro (B), com água quente, antes de serem determinados por meio de absorção atômica no Laboratório de Fertilidade do Solo do IAC.
- Ponto de carga zero (PCZ) dos solos: utilizou-se o método proposto por CAMARGO et al. (2009) e foi realizado no Laboratório de Geologia Ambiental e Ciência do Solo da Universidade Federal de São Paulo (SP). O ponto de carga zero corresponde ao valor de $\mathrm{pH}$ no qual a carga superficial de um sistema reversível de dupla camada é zero (FONTES et al. 2001).

- Outros parâmetros: matéria orgânica (MO), analisada pelo método colorimétrico (extração com dicromato de sódio); potencial hidrogeniônico $(\mathrm{pH})$, obtido em solução de $\mathrm{CaCl}_{2}$; acidez potencial ou total $(\mathrm{H}+\mathrm{Al})$, determinado por meio de solução tampão SMP e potenciometria; soma de bases (SB), pelo cálculo: $\mathrm{Ca}+\mathrm{Mg}+\mathrm{K}$; capacidade de troca de cátions $(\mathrm{CTC})$, pelo cálculo: $\mathrm{SB}+(\mathrm{H}+\mathrm{Al})$, e porcentagem da CTC saturada por bases a $\mathrm{pH} 7$ (V\%), calculada por $\mathrm{V} \%=100 /(\mathrm{SB} / \mathrm{CTC})$. Todos esses parâmetros foram obtidos no Laboratório de Fertilidade do Solo do IAC.

2.2 Caracterização das amostras de vermiculita e zeólita

As amostras de vermiculita foram fornecidas pela empresa Urimamã Mineração Ltda. na forma in natura e fração de $1 \mathrm{~mm}$ de granulometria. As amostras contendo zeólita são provenientes de Cuba e comercializadas pela empresa Celta Brasil, e também foram utilizadas na forma in natura e na fração entre 1 e 0,4 mm.

A composição química das amostras de vermiculita e zeólita foi determinada por fluorescência de raios $\mathrm{X}$ no equipamento PANalytical, modelo Axios Advanced do Laboratório de Caracterização Tecnológica da Escola Politécnica da Universidade de São Paulo. A capacidade de troca catiônica (CTC) das duas amostras foi determinada pelo método proposto por FARKAS et al. (2005), onde para cada $1 \mathrm{~g}$ de mineral foram adicionados $40 \mathrm{ml}$ de solução 2 mol.L $\mathrm{L}^{-1}$ de $\mathrm{NH}_{4} \mathrm{Cl}$. As misturas foram mantidas em agitação por $2 \mathrm{~h}$ e, em seguida, centrifugadas e lavadas com água destilada e filtradas. Adicionou-se $40 \mathrm{~mL}$ de solução 2 mol. $\mathrm{L}^{-1}$ de $\mathrm{KCl}$ às amostras lavadas e as misturas foram, mais uma vez, mantidas em agitação por $2 \mathrm{~h}$. Após esse período, as amostras foram centrifugadas e as concentrações de $\mathrm{NH}_{4}^{+}$deslocado dos sítios de troca foram determinadas por meio de espectrofotometria (HI83215/HANNA Instruments). Os resultados foram convertidos a miliequivalente por grama (meq. $\mathrm{g}^{-1}$ ), para expressarem os respectivos valores da capacidade de troca catiônica. 


\subsection{Trabalhos experimentais}

\section{Teste de lixiviação de $\mathrm{K}^{+}$em colunas com solos}

Uma vez que a seletividade dos componentes do solo por determinados íons pode fornecer informações sobre a mobilidade/lixiviação (perdas) do potássio no meio (JALALI \& ROWELL 2003), o presente teste teve o objetivo de estudar a dinâmica do potássio em função das propriedades físicas (textura), químicas e mineralógicas do solo.

Unidades experimentais compostas por colunas de politereftalato de etileno (PET) com 5,5 cm de diâmetro e $20 \mathrm{~cm}$ de comprimento foram montadas devidamente limpas com $\mathrm{HCl}$ diluído e água destilada e secas. O fundo de cada coluna foi revestido com base de tela fina e filtro de papel para evitar perdas de material sólido.

Preparou-se 4 colunas preenchidas com 325 $\mathrm{cm}^{3}$ de solo seco e peneirado (malha $2 \mathrm{~mm}$ ). A coluna 1 (referência) recebeu somente solo; na coluna 2 acrescentou-se, além do solo, uma fonte de potássio ( $1 \mathrm{~g}$ de $\mathrm{KCl}$ ); na coluna 3 foi adicionado ao solo $5 \mathrm{~g}$ de vermiculita e $1 \mathrm{~g}$ de $\mathrm{KCl}$; o solo da coluna 4 foi tratado com $5 \mathrm{~g}$ de zeólita, além de receber $1 \mathrm{~g}$ de $\mathrm{KCl}$.

As colunas foram preenchidas gradualmente com auxílio de água destilada e a mistura compactada a cada fração (cerca de $2 \mathrm{~cm}$ ), de forma a manter a homogeneidade do meio e evitar a formação de espaços vazios. Todas as colunas permaneceram saturadas com água destilada até a formação de uma fina película de água na superfície do solo, sob temperatura e pressão ambientes. Após 24 h, as soluções foram drenadas e recolhidas, e o seu volume, $\mathrm{pH}$ e concentração de potássio determina- dos. As colunas foram preenchidas novamente com água e repetiu-se todo o processo por duas semanas (14 dias).

A concentração de potássio foi determinada com o auxílio do medidor de íon específico Compact Ion Meter Cardy ${ }^{\circledR}$ da Horiba e o pH, no equipamento HI 2221 (Hanna).

\section{Testes de incubação de solo}

Nesse experimento foi feita a incubação de solos com vermiculita e zeólita para verificar a interação desses minerais com o potássio adicionado ao meio.

Como é de costume corrigir os solos de natureza ácida por meio de calagem, utilizando-se, por exemplo, $\mathrm{CaCO}_{3}$, também foram preparados sistemas contendo esse componente. Em recipientes plásticos de $300 \mathrm{~mL}$ de capacidade foram introduzidos $100 \mathrm{~g}$ de amostra de solo (Latossolo Vermelho) e $0,5 \mathrm{~g}$ de uma fonte de potássio na forma de sal $(\mathrm{KCl})$. Adicionou-se também 2,5 g de vermiculita ou de zeólita à mistura e $0,5 \mathrm{~g}$ de $\mathrm{CaCO}_{3}$, conforme a Tabela 1 .

Algumas reações de adsorção envolvem vários parâmetros e podem ocorrer em várias escalas de tempo (segundos a meses), já que a cinética de sorção pode ser afetada pelas propriedades estruturais dos minerais (SPARKS 1995). Por exemplo, para caulinita, óxidos, hidróxidos e substâncias húmicas, a cinética de sorção de metais geralmente é rápida, ao contrário do que ocorre com a vermiculita e micas, que possuem duas áreas de adsorção (externa e interna).

Assim, para garantir que o potássio solúvel proveniente do fertilizante pudesse reagir com os

TABELA 1 - Proporções dos componentes das amostras preparadas para o teste de incubação do Latossolo Vermelho $(\mathrm{Lt})$.

\begin{tabular}{|c|c|c|c|c|c|c|}
\hline & \multirow[t]{2}{*}{ Sistema } & Solo & $\begin{array}{c}\text { Vermiculita } \\
\text { natural }\end{array}$ & $\begin{array}{l}\text { Zeólita } \\
\text { natural }\end{array}$ & $\mathrm{KCl}$ & $\mathrm{CaCO}_{3}$ \\
\hline & & \multicolumn{5}{|c|}{ (g) } \\
\hline $1-$ & $L t$ & 100 & - & - & - & - \\
\hline $2-$ & $L t-K$ & 100 & - & - & 0,5 & - \\
\hline $3-$ & $L t-K-V e r$ & 100 & 2,5 & - & 0,5 & - \\
\hline $4-$ & $L t-K-Z e o$ & 100 & - & 2,5 & 0,5 & - \\
\hline $5-$ & $L t-K-V e r-C a$ & 100 & 2,5 & - & 0,5 & 0,5 \\
\hline $6-$ & $\mathrm{Lt}-\mathrm{K}-\mathrm{Zeo}-\mathrm{Ca}$ & 100 & - & 2,5 & 0,5 & 0,5 \\
\hline
\end{tabular}


minerais do solo, além daqueles adicionados (vermiculita e zeólita), os materiais permaneceram em contato durante 30 dias. Cada sistema foi homogeneizado e, em seguida, recebeu $10 \mathrm{~mL}$ de água deionizada, permanecendo incubado à temperatura ambiente durante o período.

A cada 5 dias coletou-se uma fração de cada sistema, que foi seca a temperatura ambiente; em seguida, $1 \mathrm{~g}$ dessa amostra foi misturada à $15 \mathrm{~mL}$ de água deionizada por $24 \mathrm{~h}$. Este método, adaptado de MA \& RAO (1997), permite determinar a concentração de K-solúvel. Para medir o $\mathrm{pH}$ do solo em água, utilizou-se a mesma amostra seca e a proporção de solo:água deionizada igual a 1:2,5 (CAMARGO et al. 2009).

\section{RESULTADOS E DISCUSSÃO}

\subsection{Caracterização do solo}

A análise dos difratogramas de raios $\mathrm{X}$ revelou presença de minerais ricos em ferro, como hematita $\left(\mathrm{Fe}_{2} \mathrm{O}_{3}\right)$, magnetita $\left(\mathrm{Fe}_{3} \mathrm{O}_{4}\right)$ e goethita $\mathrm{FeO}(\mathrm{OH})$, além de caulinita $\left(\mathrm{Al}_{2} \mathrm{Si}_{2} \mathrm{O}_{5}(\mathrm{OH})_{4}\right)$, gibbsita $\left(\mathrm{Al}(\mathrm{OH})_{3}\right)$, quartzo $\left(\mathrm{SiO}_{2}\right)^{2}$ e anatásio $\left(\mathrm{TiO}_{2}\right)$. Nas condições de realização dessa análise não se observou nenhuma importante fonte de $\mathrm{K}^{+}$ proveniente de minerais.

Os resultados da análise química dos solos (Tabela 2) estão de acordo com a sua composição mineralógica, onde se observa a presença significativa de $\mathrm{SiO}_{2}, \mathrm{Fe}_{2} \mathrm{O}_{3}$ e $\mathrm{Al}_{2} \mathrm{O}_{3}$.
TABELA 2 - Análise química do Latossolo Vermelho. Valores expressos em \% de óxidos, normalizados a $100 \%$.

\begin{tabular}{cc}
\hline Amostra & Latossolo vermelho (\%) \\
\hline $\mathrm{SiO}_{2}$ & 31,30 \\
$\mathrm{Al}_{2} \mathrm{O}_{3}$ & 22,60 \\
$\mathrm{Fe}_{2} \mathrm{O}_{3}$ & 27,40 \\
$\mathrm{MnO}$ & 0,18 \\
$\mathrm{MgO}$ & 0,15 \\
$\mathrm{CaO}$ & 0,12 \\
$\mathrm{Na}_{2} \mathrm{O}$ & 0,20 \\
$\mathrm{~K}_{2} \mathrm{O}$ & $<0,10$ \\
$\mathrm{TiO}_{2}$ & 6,78 \\
$\mathrm{P}_{2} \mathrm{O}_{5}$ & 0,23 \\
$\mathrm{PF} \mathrm{a} 1050^{\circ} \mathrm{C}$ & 11,90 \\
\hline
\end{tabular}

Apesar do Latossolo Vermelho ser considerado um dos solos mais férteis do Estado de São Paulo (KER 1997), seus valores de potássio e de fósforo são relativamente baixos (Tabela 3). As concentrações do íon potássio são da ordem de 2,9 $\mathrm{mmol}_{\mathrm{c}} \cdot \mathrm{dm}^{-3}$, que corresponde à cerca de $58 \mathrm{mg} \cdot \mathrm{Kg}^{-1}$ ou $0,0058 \%$, abaixo do limite de detecção do método de análise química por fluorescência de raios $\mathrm{X}$. Provavelmente o $\mathrm{K}^{+}$determinado nessa análise encontra-se associado à matéria orgânica ou adsorvido nos óxidos e/ou colóides do solo, uma vez que na composição mineralógica do solo não foi identificado nenhuma fonte importante desse elemento.

TABELA 3 - Análise de pH, PCZ, teor de matéria orgânica (MO), acidez total ( $\mathrm{H}+\mathrm{Al})$, soma de bases (SB), capacidade de troca catiônica $(\mathrm{CTC})$, saturação de bases $(\mathrm{V})$, potássio $(\mathrm{K})$, cálcio $(\mathrm{Ca})$, magnésio $(\mathrm{Mg})$, fósforo $(\mathrm{P})$, enxofre $(\mathrm{S})$, boro $(\mathrm{B})$, cobre $(\mathrm{Cu})$, ferro $(\mathrm{Fe})$, manganês $(\mathrm{Mn})$ e zinco $(\mathrm{Zn})$ nas amostras de latossolo $(\mathrm{Lt})$.

\begin{tabular}{|c|c|c|c|c|c|c|c|c|c|c|c|c|c|c|c|c|}
\hline$p H$ & $P C Z$ & $\begin{array}{c}M O \\
\left(g . d m^{-3}\right)\end{array}$ & $H+A l$ & $\begin{array}{c}S B \\
\text { nol }_{c} \cdot d n\end{array}$ & $C T C$ & $\begin{array}{c}V \\
(\%)\end{array}$ & & $\begin{array}{c}\mathrm{Ca} \\
\text { nol. }_{c} \text {. }\end{array}$ & $\begin{array}{l}M g \\
3)\end{array}$ & $P$ & $S$ & $B$ & $\begin{array}{c}C u \\
m g . d n\end{array}$ & $\mathrm{Fe}$ & $M n$ & $Z n$ \\
\hline 5,4 & 4,6 & 18 & 20 & 37,7 & 58,0 & 65 & 2,9 & 29 & 6 & 5 & 3 & 0,18 & 6,1 & 11 & 23,7 & 0,4 \\
\hline
\end{tabular}

O teor de cálcio trocável disponível no solo é considerado alto $\left(>7 \mathrm{mmol}_{\mathrm{c}} \cdot \mathrm{dm}^{-3}\right)$, enquanto o de magnésio, médio (entre 5 e $8 \mathrm{mmol}_{\mathrm{c}} \cdot \mathrm{dm}^{-3}$ ) (IAC 2012). Quanto aos micronutrientes, o latossolo apresenta altos teores em cobre, ferro, zinco e manganês. Todos esses íons, de certa forma, encontram-se na fase trocável do solo e não necessariamente estão associados à estrutura de uma fase mineral.

$\mathrm{O}$ pH do solo estudado é considerado de média acidez $\left(5,4 \mathrm{em} \mathrm{CaCl}_{2}\right)$, assim como sua saturação por bases $(\mathrm{V}=65 \%)$, revelando que ambos os parâmetros apresentam estreita correlação entre si (IAC 2012).

$\mathrm{O}$ valor de ponto de carga zero foi de 4,6 e assemelha-se aos valores obtidos por ALMEIDA et al. (2009) para o Latossolo Vermelho da região de Jaboticabal: 4,8 (0 e $10 \mathrm{~cm}$ de profundidade) e $4,2(10-20 \mathrm{~cm})$.

Conforme a classificação textural proposta por CAMARGO et al. (2009), o latossolo possui textura argilosa (Tabela 4). 
TABELA 4 - Frações granulométricas do Latossolo Vermelho (Lt).

\begin{tabular}{ccccc}
\hline Identificação & $\begin{array}{c}\text { Argila \% } \\
<0,002 \mathrm{~mm}\end{array}$ & $\begin{array}{c}\text { Silte \% } \\
0,053-0,002 \mathrm{~mm}\end{array}$ & $\begin{array}{c}\text { Areia total \% } \\
2,00-0,053 \mathrm{~mm}\end{array}$ & $\begin{array}{c}\text { Classificação } \\
\text { textural }\end{array}$ \\
\hline$L t$ & 56,5 & 17,3 & 26,2 & Argila \\
\hline
\end{tabular}

3.2 Caracterização das amostras de vermiculita e zeólita

As análises químicas das amostras de zeólita e de vermiculita revelam que ambas apresentam baixos teores de $\mathrm{K}_{2} \mathrm{O}$ em suas composições (Tabela 5).

TABELA 5 - Composições químicas das amostras de zeólita e vermiculita. Valores expressos em \% de óxidos.

\begin{tabular}{ccc}
\hline Amostra & $\begin{array}{c}\text { Zeólita } \\
(\%)\end{array}$ & $\begin{array}{c}\text { Vermiculita } \\
(\%)\end{array}$ \\
\hline $\mathrm{Al} \mathrm{O}_{2}{ }_{3}$ & 11,6 & 16,4 \\
$\mathrm{SiO}_{2}$ & 68,5 & 36,4 \\
$\mathrm{~K} \mathrm{O}_{2}$ & 1,19 & 4,55 \\
$\mathrm{MgO}$ & 0,76 & 11,9 \\
$\mathrm{CaO}$ & 2,88 & 0,76 \\
$\mathrm{Fe} \mathrm{O}_{2}$ & 1,52 & 17,3 \\
$\mathrm{TiO}_{2}$ & 0,28 & 1,23 \\
$\mathrm{POO}_{2}$ & $<0,10$ & 0,04 \\
$\mathrm{Na}_{2} \mathrm{O}$ & 1,34 & 0,23 \\
$\mathrm{BaO}$ & - & 0,24 \\
\hline Perda ao & 11,3 & 10,6 \\
Fogo $1050^{\circ} \mathrm{C}$ & & \\
\hline
\end{tabular}

O potássio presente na amostra de vermiculita pode estar associado à presença de minerais interestratificados de vermiculita e micas (biotita ou flogopita), já identificados em trabalho anterior (SHINZATO et al. 1999). Conforme WU (2013), a amostra de zeólita é composta por $98 \%$ de clinoptilolita e $2 \%$ de mordenita, tendo como íons na posição trocável o cálcio e, secundariamente, sódio e potássio.

O valor de capacidade de troca catiônica (CTC) da amostra com zeólita é superior ao da vermiculita (Tabela 6), fato já esperado, uma vez que a primeira possui microporos em sua estrutura, que elevam a sua superfície específica. No caso da amostra de vermiculita, o processo de troca iônica ocorre principalmente nos espaços interlamelares. No entanto, apesar da menor CTC, esse valor ainda é muito superior ao do solo estudado $\left(58 \mathrm{mmol}_{\mathrm{c}}\right.$. $\mathrm{dm}^{-3}$ ), em função da presença de minerais de baixa CTC como, argilominerais 1:1, óxidos de ferro e oxi-hidróxidos de ferro.

TABELA 6 - Valores de CTC determinados para as amostras de zeólita e de vermiculita expressos em meq.g $\mathrm{g}^{-1}$ e $\mathrm{mmol}_{\mathrm{c}} \cdot \mathrm{dm}^{-3}$.

\begin{tabular}{ccc}
\hline Amostra & $\begin{array}{c}\text { CTC } \\
\left(\text { meq. } g^{-1}\right)\end{array}$ & $\begin{array}{c}\text { CTC } \\
\left(\text { mmol }_{c} \mathrm{dm}^{-3}\right)\end{array}$ \\
\hline Zeólita & 2,49 & $2.490,00$ \\
Vermiculita & 0,26 & 260,00 \\
\hline
\end{tabular}

\subsection{Trabalhos experimentais}

\section{Teste de lixiviação de $\mathrm{K}^{+}$em colunas com solos}

Verificou-se, ao longo do período de percolação de água, que o íon potássio foi pouco lixiviado do solo (coluna 1 - Tabela 7), o que corrobora os dados químicos do latossolo estudado, que indicam baixas concentrações de $\mathrm{K}^{+}$disponível. No entanto, com a introdução de uma fonte de $\mathrm{K}^{+}$no solo, verificou-se que esse nutriente passou a ser gradualmente liberado, quando submetido ao processo de lixiviação com água (coluna 2 Tabela 7). Essa quantidade liberada, por sua vez, é muito baixa em relação àquela introduzida no solo (524 mg de $\mathrm{K}^{+}$), que, em grande parte, ainda permanece retida na fase sólida do meio. De forma geral, a perda de $\mathrm{K}^{+}$para a fração solúvel em cada ciclo de lixiviação foi, em média, de somente $2 \%$, perfazendo cerca de $28 \%$ do total introduzido no sistema ao final dos 14 ciclos. Possivelmente isso se deve à presença de óxidos e hidróxidos na composição do solo, cuja adsorção depende do $\mathrm{pH}$ do meio. Como todos os pHs do meio estão acima do PCZ determinado para o latossolo $(4,6)$, acredita-se que os sólidos presentes tenham ad- 
TABELA 7 - Valores de pH, concentração $\left(m g . \mathrm{L}^{-1}\right)$ e porcentagem de $\mathrm{K}^{+}$lixiviado das colunas contendo somente Latossolo Vermelho (Lt), latossolo com fonte de potássio $(\mathrm{Lt}+\mathrm{K})$, vermiculita $(\mathrm{Lt}+\mathrm{ver}+\mathrm{K})$ e zeólita $(\mathrm{Lt}+\mathrm{Zeo}+\mathrm{K})$.

\begin{tabular}{|c|c|c|c|c|c|c|c|c|c|c|c|}
\hline \multirow{2}{*}{ Período } & \multicolumn{2}{|c|}{$\begin{array}{c}\text { Coluna } 1 \\
(L t)\end{array}$} & \multicolumn{3}{|c|}{$\begin{array}{c}\text { Coluna } 2 \\
(L t+K)\end{array}$} & \multicolumn{3}{|c|}{$\begin{array}{c}\text { Coluna } 3 \\
(L t+v e r+K)\end{array}$} & \multicolumn{3}{|c|}{$\begin{array}{c}\text { Coluna } 4 \\
(L t+z e o+K)\end{array}$} \\
\hline & $p H$ & $\begin{array}{c}{[K]} \\
m g \cdot L^{-1}\end{array}$ & $p H$ & $\begin{array}{c}{[K]} \\
m g \cdot L^{-1}\end{array}$ & {$[K] \%$} & $p H$ & $\begin{array}{c}{[K]} \\
m g \cdot L^{-1}\end{array}$ & $\begin{array}{c}{[K]} \\
\%\end{array}$ & $p H$ & $\begin{array}{c}{[K]} \\
m g \cdot L^{-1}\end{array}$ & {$[K] \%$} \\
\hline $1^{\circ} \mathrm{dia}$ & 5,8 & 0,080 & 6,6 & 36,90 & 7,04 & 5,2 & 15,96 & 3,05 & 6,0 & 4,94 & 0,94 \\
\hline $2^{\circ} d i a$ & 6,0 & 0,072 & 6,5 & 15,40 & 2,94 & 5,0 & 9,60 & 1,83 & 6,1 & 7,29 & 1,39 \\
\hline $3^{\circ}$ dia & 5,5 & 0,084 & 6,4 & 15,00 & 2,86 & 5,2 & 13,30 & 2,54 & 6,0 & 6,00 & 1,15 \\
\hline $4^{\circ} d i a$ & 5,9 & 0,060 & 6,5 & 14,70 & 2,81 & 5,3 & 7,60 & 1,45 & 6,2 & 7,20 & 1,37 \\
\hline $5^{\circ} d i a$ & 5,9 & 0,014 & 6,3 & 5,60 & 1,07 & 5,1 & 10,80 & 2,06 & 6,0 & 8,40 & 1,60 \\
\hline $6^{\circ} d i a$ & 6,0 & 0,014 & 6,3 & 3,80 & 0,73 & 5,6 & 7,50 & 1,43 & 6,2 & 8,40 & 1,60 \\
\hline $7^{\circ}$ dia & 5,6 & 0,048 & 6,5 & 4,00 & 0,76 & 5,5 & 4,50 & 0,86 & 6,2 & 5,60 & 1,07 \\
\hline $8^{\circ} d i a$ & 5,8 & 0,036 & 6,4 & 12,60 & 2,40 & 5,2 & 6,40 & 1,22 & 6,1 & 4,20 & 0,80 \\
\hline $9^{\circ} d i a$ & 5,6 & 0,018 & 6,6 & 4,80 & 0,92 & 5,4 & 7,50 & 1,43 & 6,3 & 5,60 & 1,07 \\
\hline $10^{\circ} \mathrm{dia}$ & 5,7 & 0,014 & 6,5 & 8,50 & 1,62 & 5,1 & 9,00 & 1,72 & 6,2 & 9,80 & 1,87 \\
\hline $11^{\circ} \mathrm{dia}$ & 5,5 & 0,000 & 6,5 & 3,20 & 0,61 & 5,2 & 6,00 & 1,15 & 6,1 & 5,60 & 1,07 \\
\hline $12^{\circ} \mathrm{dia}$ & 6,0 & 0,000 & 6,6 & 1,70 & 0,32 & 5,3 & 7,50 & 1,43 & 6,3 & 5,60 & 1,07 \\
\hline $13^{\circ} \mathrm{dia}$ & 6,3 & 0,000 & 6,8 & 12,50 & 2,39 & 5,3 & 6,00 & 1,15 & 6,2 & 6,50 & 1,24 \\
\hline $14^{\circ} \mathrm{dia}$ & 5,8 & 0,000 & 6,6 & 9,50 & 1,81 & 5,1 & 6,40 & 1,22 & 6,1 & 4,20 & 0,80 \\
\hline $\begin{array}{c}\text { Total de } K^{+} \\
\text {lixiviado }\end{array}$ & & 0,439 & & 148,20 & 28,28 & & 118,10 & 22,54 & & 89,30 & 17,04 \\
\hline $\begin{array}{l}\text { Total de } K^{+} \\
\quad \text { retido }\end{array}$ & & & & & 71,72 & & & 77,46 & & & 82,96 \\
\hline
\end{tabular}

quirido cargas superficiais negativas e promovido a retenção de $\mathrm{K}^{+}$pela fração trocável do solo. Vários trabalhos também têm apontado os óxidos de ferro e alumínio presentes no Latossolo Vermelho como responsáveis na retenção de diferentes cátions, como cobre (SILVEIRA \& ALEONI 2003) e arsênio (DESCHAMPS et al. 2005).

Durante o período analisado (14 ciclos de $24 \mathrm{~h}$ ) verificou-se que o processo de lixiviação de potássio permaneceu constante desde o $2^{\circ}$ ou $3^{\circ}$ dias em todas as colunas testadas.

Apesar da textura argilosa, o solo em questão apresentou uma boa permeabilidade, permitindo a coleta de cerca de $6 \mathrm{~mL}$ de solução em cada ciclo de lixiviação. FERREIRA et al. (1999) também verificaram em seus estudos que a permeabilidade dos latossolos aumenta com o teor de argila. Isso se deve ao fato da presença de uma estrutura granular muito pequena e bem expres- sa em latossolos que, mesmo quando muito argilosos, lhes confere uma grande permeabilidade (RESENDE 1985). Por outro lado essa textura também pode ter contribuído com o aumento da retenção do potássio, uma vez que a elevada superfície específica das partículas favorece a adsorção de íons em solução.

No sistema contendo vermiculita, a média de $\mathrm{K}^{+}$solubilizado em cada ciclo foi de $1,6 \%$, e com zeólita, $1,2 \%$, revelando a participação da fase fixa na retenção desse íon no solo.

Grande parte do $\mathrm{K}^{+}$liberado pela dissolução do $\mathrm{KCl}$ adicionado no solo foi rapidamente transferida para a fração trocável, uma vez que as concentrações medidas nas soluções recolhidas na coluna 2 permaneceram sempre baixas. Outra parte pode ter sido transferida para a fase não-trocável (colunas 3 e 4), ficando retida nas estruturas da vermiculita ou da zeólita. 
Essa constatação também é compartilhada por JOHNSTON \& GOULDING (1990), que observaram que a presença de minerais com elevada CTC aumenta a capacidade de retenção do potássio no solo.

A presença da vermiculita e da zeólita aumentou a retenção de $\mathrm{K}^{+}$, de cerca de $72 \%$ para $77 \%$ e $83 \%$, respectivamente. As curvas cumulativas de perda de $\mathrm{K}^{+}$(Figura 1) ilustram bem as diferenças nos sistemas estudados.

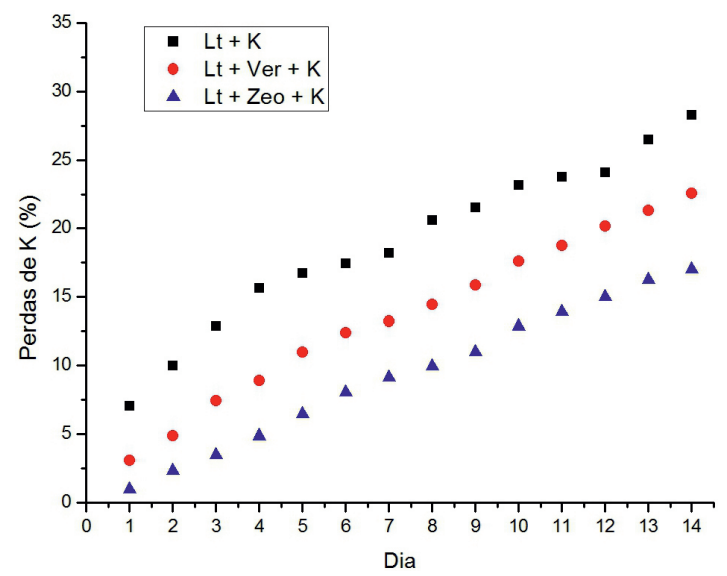

FIGURA 1 - Curvas cumulativas de perdas de potássio nos sistemas contendo latossolo e fonte de potássio $(\mathrm{Lt}+\mathrm{K})$, latossolo + vermiculita + potássio $(\mathrm{Lt}+\mathrm{Ver}+\mathrm{K})$ e latossolo + zeólita + potássio $(\mathrm{Lt}+\mathrm{Zeo}+\mathrm{K})$.

Em geral, o pH ficou um pouco mais ácido nas soluções de lixiviação em solos com adição de vermiculita. Isso se deve, provavelmente, à influência da presença de sítios doadores de prótons (ácido de Brønsted) e receptores de elétrons (ácido de Lewis) (MORENO \& RAJAGOPAL 2009) nas posições de troca da estrutura desses minerais (espaço interfoliar), originados pela substituição isomórfica de Si por Al nas folhas de tetraedros. Apesar das zeólitas também apresentarem sítios ácidos em sua estrutura, não se observou uma diminuição significativa nos valores de $\mathrm{pH}$ das soluções de lixiviação.

Assim, verificou-se que o fato da maior parte do $\mathrm{K}^{+}$passar para as frações trocáveis e não-trocáveis do solo contribui na diminuição de sua lixiviação, possibilitando disponibilizá-lo por mais tempo para as plantas e, consequentemente, reduzir os gastos com fertilizantes.

\section{Solos incubados com vermiculita e zeólita}

Para melhor visualizar e analisar os resultados obtidos nesse experimento, as concentrações de potássio da fase solúvel determinadas ao longo do tempo (Tabela 8) estão representadas nos gráficos da figura 2.

Em todo o período analisado o $\mathrm{pH}$ do solo de referência $(\mathrm{Lt})$ permaneceu pouco ácido e não apresentou nenhum potássio lixiviado, devido à indisponibilidade desse nutriente em sua composição original. No sistema em que $\mathrm{o} \mathrm{K}^{+}$foi adicionado (Lt-K), as concentrações desse nutriente, determinadas na fase solúvel, permaneceram quase constantes ao longo do tempo, revelando que não ocorreram muitas reações capazes de alterar a disponibilidade de $\mathrm{K}^{+}$nesse meio. Apenas uma pequena porcentagem permaneceu na fase solúvel (em torno de $7,5 \%$ do total de $\mathrm{K}^{+}$adicionado ao solo), corroborando os dados obtidos no teste de lixiviação em colunas.

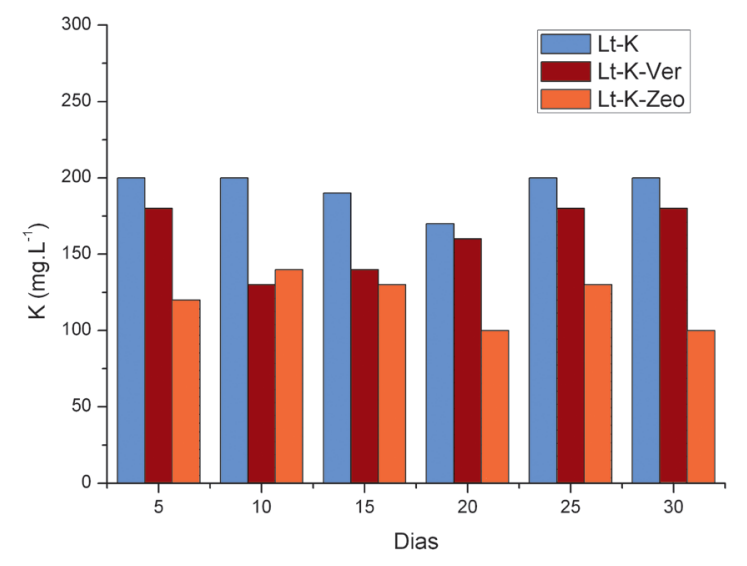

FIGURA 2 - Valores de concentração de potássio (mg.L $\left.\mathrm{L}^{-1}\right)$ presente na fase solúvel em função do tempo de incubação dos sistemas contendo Latossolo Vermelho com fonte de potássio (Lt-K), vermiculita (Lt-K-Ver), zeólita (Lt-K-Zeo) e carbonato de cálcio (Lt-K-Ver-Ca e Lt-K-Zeo-Ca).

A adição de minerais com elevada CTC, como vermiculita e zeólita, contribuiu com a diminuição da perda de $\mathrm{K}^{+}$para a fase solúvel, uma vez que parte desse nutriente ficou retida nos sítios de troca desses minerais, ou seja, na fração fixa do solo.

Apesar de autores como MENGEL \& UHLENBECKER (1993) e JALALI (2006) afir- 
TABELA 8 - Valores de $\mathrm{pH}$ e concentração de potássio $\left(\mathrm{mg} . \mathrm{L}^{-1}\right)$ determinados nas fases solúveis do solo em períodos entre 5 e 30 dias. Os valores de $\% \mathrm{~K}$ correspondem à fração liberada em cada sistema em relação à concentração total lixiviada no período em cada sistema.

\begin{tabular}{|c|c|c|c|c|c|c|c|c|c|c|c|c|c|c|c|c|c|c|c|c|}
\hline \multirow{3}{*}{ Sistema } & \multicolumn{3}{|c|}{5 dias } & \multicolumn{3}{|c|}{10 dias } & \multicolumn{3}{|c|}{15 dias } & \multicolumn{3}{|c|}{20 dias } & \multicolumn{3}{|c|}{25 dias } & \multicolumn{3}{|c|}{30 dias } & \multirow{2}{*}{\multicolumn{2}{|c|}{$\begin{array}{c}\text { Total } \\
{[K]}\end{array}$}} \\
\hline & \multirow[t]{2}{*}{$p H$} & \multirow{2}{*}{\multicolumn{2}{|c|}{$\frac{[K]}{\left(m g \cdot L^{-}\right)^{1} \%}$}} & \multirow[t]{2}{*}{$p H$} & \multicolumn{2}{|c|}{$[K]$} & \multirow[t]{2}{*}{$p H$} & \multirow{2}{*}{\multicolumn{2}{|c|}{$\frac{[K]}{\left(m g \cdot L^{-1}\right) \%}$}} & \multirow[t]{2}{*}{$p H$} & & {$[K]$} & \multirow[t]{2}{*}{$p H$} & \multirow{2}{*}{\multicolumn{2}{|c|}{$\frac{[K]}{\left(m g \cdot L^{-1}\right) \%}$}} & \multirow[t]{2}{*}{$p H$} & \multirow{2}{*}{\multicolumn{2}{|c|}{$\frac{[K]}{\left(m g \cdot L^{-1}\right) \%}$}} & & \\
\hline & & & & & $\overline{(m g . L}$ & $\%$ & & & & & & & & & & & & & \multicolumn{2}{|c|}{$\left(m g \cdot L^{-1}\right) \%$} \\
\hline$\overline{L t}$ & 5,4 & nd & & 6,4 & nd & 0 & 6,6 & nd & 0 & 6,5 & nd & & & $\mathrm{nd}$ & & 6,5 & nd & 0 & 0 & 0 \\
\hline$L t-K$ & 6,8 & 200 & 7,63 & 6,7 & 200 & 7,63 & 6,3 & 190 & 7,25 & 6,4 & 170 & 6,49 & 6,9 & 200 & 7,63 & 6,6 & 200 & 7,63 & 1160 & 45,67 \\
\hline$L t-K-I$ & 55 & 180 & 6,87 & 5,7 & 130 & 10 & 6,3 & 140 & 5,34 & 6,0 & 160 & 611 & 58 & 180 & 6,87 & 6,2 & 180 & 6,87 & 970 & 38,17 \\
\hline$L t-K-Z e o$ & 5,0 & 120 & 4,58 & 5,0 & 140 & 5,34 & 5,4 & 130 & 4,96 & 5,3 & 100 & 3,82 & 5,3 & 130 & 4,96 & 5,1 & 100 & 3,82 & 720 & 28,38 \\
\hline$L t-K-\mathrm{Ver}$ & 6,7 & 200 & 7,63 & 6,9 & 240 & 9,16 & 7,0 & 210 & 8,02 & 7,1 & 180 & 6,87 & 7,0 & 250 & 9,54 & 7,1 & 190 & 7,25 & 1270 & 50,05 \\
\hline$L t-K-Z e o-C a$ & 6,9 & 130 & 4,96 & 7,2 & 180 & 6,87 & 6,9 & 190 & 7,25 & 6,9 & 110 & 4,20 & 7,1 & 170 & 6,49 & 6,8 & 120 & 4,58 & 900 & 35,49 \\
\hline
\end{tabular}

$\mathrm{Lt}=$ latossolo; $\mathrm{Lt}-\mathrm{K}=$ latossolo com fonte de potássio; $\mathrm{Lt}-\mathrm{K}-\mathrm{Ver}=$ latossolo com potássio e vermiculita; Lt-K$\mathrm{Zeo}=$ latossolo com potássio e zeólita, Lt-K-Ver-Ca = latossolo com potássio, vermiculita e fonte de carbonato de cálcio; Lt-K-Zeo-Ca = latossolo com potássio, zeólita e fonte de carbonato de cálcio; nd= não detectado.

marem que o $\mathrm{K}^{+}$fixo em certos filossilicatos constituem importante reserva de $\mathrm{K}^{+}$para o solo, BOHN et al. (2001) ressaltam que a lenta liberação desse nutriente pode não satisfazer totalmente as necessidades das plantas. No entanto, cabe ressaltar que as condições de clima tropical (temperatura elevada e maior disponibilidade de água) podem acelerar o processo de liberação desse íon com a alteração desses minerais.

A presença de $\mathrm{Ca}^{2+}$ proveniente de corretivos de $\mathrm{pH}$ do solo pode interferir na retenção de $\mathrm{K}^{+}$pela vermiculita, já que os seus sítios de troca dão preferência a cátions com maior grau de hidratação e valência (GRIM 1968). Esse comportamento pôde ser atestado em todo o período analisado (Figura 2).

JALALI (2006) também observou que na presença de $\mathrm{Ca}^{2+}$, o $\mathrm{K}^{+}$dos argilominerais como vermiculitas e ilitas eram mais facilmente lixiviados. Segundo o autor esse comportamento deve-se ao fato do cálcio ser mais hidratado que o potássio e ao migrar para a região interfoliar da estrutura dos filossilicatos, acaba provocando a sua expansão, liberando $\mathrm{o} \mathrm{K}^{+}$retido nesses sítios.

Por outro lado, a adição da zeólita no meio, apesar de diminuir um pouco o $\mathrm{pH}$, promoveu maior retenção de $\mathrm{K}^{+}$disponível, mesmo na presença de cálcio. Os sítios de troca das estruturas das zeólitas, ao contrário das vermiculitas, possuem preferência por íons de menor carga (SHERRY 1979) e por isso o processo de troca não foi afetado pela presença do cálcio, introduzido para corrigir o $\mathrm{pH}$ do solo.

\section{CONSIDERAÇÕES FINAIS}

As características do solo como composição mineralógica, CTC e textura influenciam nas formas de $\mathrm{K}^{+}$disponível e, consequentemente, no suprimento desse nutriente para as plantas. O latossolo estudado não apresenta reservas importantes de $\mathrm{K}^{+}$e nem minerais com elevada CTC. No entanto, quando um sal de potássio solúvel é adicionado ao solo, a perda desse íon por lixiviação não é tão significativa, devido à presença de óxidos e hidróxidos de ferro na sua composição, que o retém na fase trocável.

A passagem do $\mathrm{K}^{+}$solúvel para a forma não trocável (estruturas da vermiculita e zeólita) é rápida e eficiente, garantindo que parte desse íon permaneça no solo como uma reserva.

A presença de $\mathrm{Ca}^{2+}$ usado para corrigir o $\mathrm{pH}$ do solo, entretanto, pode afetar o processo de troca iônica nas vermiculitas, que preferem cátions de maior valência em detrimento dos monovalentes, como é o caso do potássio. Por outro lado, os sítios de troca das zeólitas do tipo clinoptilolita preferem íons de menor valência, como o $\mathrm{K}^{+}$, por possuírem menor energia de hidratação, fazendo com que o $\mathrm{Ca}^{2+}$ não interfira no processo de retenção desse nutriente em sua estrutura.

Assim sendo, a introdução de minerais de elevada CTC, como vermiculita e zeólita, se revelaram eficazes na diminuição de perdas de potássio por lixiviação. E, dentre os dois minerais, a zeólita desempenhou melhor o papel de fixação de $\mathrm{K}^{+}$e, por isso, sua aplicação é de grande interesse para a economia de fertilizantes. 


\section{AGRADECIMENTOS}

À Fundação de Amparo à Pesquisa do Estado de São Paulo (FAPESP), pelo financiamento da pesquisa (processo 2011/13168-1) e aos relatores, pelas valiosas sugestões.

\section{REFERÊNCIAS BIBLIOGRÁFICAS}

ALFARO, M.A.; JARVIS, S.C.; GREGORY, P.J. 2004. Factors affecting potassium leaching in different soils. Soil Use and Management, 20: 182-189.

ALMEIDA, C.X.; CENTURION, J.F.; JORGE, R.F.; ANDRIOLI, I.; VIDAL, A.A.; SERAFIM, R.S. 2009. Índice de floculação e agregação de um latossolo vermelho sob dois sistemas de colheita da cana-de-açúcar. Bioscience Journal, 25(4): 123-129.

ANDA - ASSOCIAÇÃO NACIONAL PARA DIFUSÃO DE ADUBOS. 2010. Investimentos no Brasil. Disponível em http://www.anda. org.br/multimidia/investimentos.pdf. Acessado em 10/jul./2013.

BOHN, H.L.; MCNEAL, B.L.; O'CONNER, G.A. 2001. Soil Chemistry. John Wiley Professional, Canada, 3rd edition, $320 \mathrm{p}$.

BOYER, J. 1991. O potássio nos solos tropicais. Instituto da Potassa, São Paulo, 9 p.

CAMARGO, O.A.; MONIZ, A.C.; JORGE, J.A.; VALADARES, J.M.A.S. 2009. Métodos de análises química, mineralógica e física de solos do Instituto Agronômico de Campinas. Campinas: Instituto Agronômico de Campinas, 77 p. (Boletim Técnico, 106).

DESCHAMPS, E.; CIMINELLI, V.S.T.; HÖLL, W.H. 2005. Removal of As(III) and As(V) from water using a natural $\mathrm{Fe}$ and $\mathrm{Mn}$ enriched sample. Water Research, 39: 5212-5220.

FARKAS, A.; ROZIC, M.; BARBARICMIKOCEVIC, Z. 2005. Ammonium exchange in leakage waters of waste dumps using natural zeolite from the Krapina region. Journal of Hazardous Materials, 117: 25-33.

FERREIRA, M.M.; FERNANDES, B.; CURI, N. 1999. Influência da mineralogia da fração ar- gila nas propriedades físicas de latossolos da região sudeste do Brasil. Revista Brasileira de Ciência do Solo, 23: 515-524.

FONTES, M.P.F.; CAMARGO, O.A.; SPOSITO, G. 2001. Eletroquímica das partículas coloidais e sua relação com a mineralogia de solos altamente intemperizados. Scientia Agricola, 58(3): 627-646.

GRIM, R.E. 1968. Clay Mineralogy. McGraw-Hill Book Company, New York, 596 p.

IAC - INSTITUTO AGRONÔMICO DE CAMPINAS. 2012. Informação sobre interpretação de análise de solo. Disponível em http:// www.iac.sp.gov.br/produtoseservicos/analisedosolo/interpretacaoanalise. php. Acessado em 30/mar./2012.

JALALI, M. 2006. Kinetics of non-exchangeable potassium release and availability in some calcareous soils of western Iran. Geoderma, 135: 63-71.

JALALI, M.; ROWELL, D.L. 2003. The role of calcite and gypsum in the leaching of potassium in a sandy soil. Experimental Agriculture, 39: 379-394.

JOHNSTON A.E.; GOULDING, K.W.T. 1990. The use of plant and soil analyses to predict the potassium supplying capacity of soil. Development of $\mathrm{K}$ fertilizer recommendations. International Potash Institute Basel Switzerland, p. 177-204.

KER, J.C. 1997. Latossolos do Brasil: Uma revisão. Geonomos, 5:17-40.

KIEHL, J.E. 1981. Preparo de composto na fazenda. Casa da Agricultura, 3: 6-9.

MA, L.Q.; RAO, G.N. 1997. Effect of phosphate rock on sequential chemical extraction of lead in contaminated soils. Journal of Environmental Quality. 26: 788-794.

MALAVOLTA, E. 1985. Potassium status of tropical and subtropical region soils. In: R.E. Munson (ed.) Potassium in Agriculture. Madinson, American Society of Agronomy, Crop Science Society of America and Soil Science Society of America, p. 163-200. 
MENGEL, K.; UHLENBECKER, K. 1993. Determination of available interlayer potassium and its uptake by ryegrass. Soil Science Society of American Journal, 57: 561-566.

MORENO, E.L.; RAJAGOPAL, K. 2009. Desafios da acidez na catálise em estado sólido. Química Nova, 32(2): 538-542.

NASCIMENTO, M.; LOUREIRO, F.E.L. 2004. Fertilizantes e Sustentabilidade: o potássio na agricultura brasileira, fontes e alternativas. CETEM/MCT, Rio de Janeiro, Série Estudos e Documentos, 66 p.

RAIJ, B.V. 1991. Fertilidade do solo e adubação. Agronômica Ceres, Piracicaba, 343 p.

RAIJ, B.V.; ANDRADE, J.C.; CANTARELLA, H.; QUAGGIO, J.A. 2001. Análise química para avaliação da fertilidade de solos tropicais. IAC, Campinas, 284 p.

RESENDE, M. 1985. Aplicações de conhecimentos pedológicos à conservação de solos. Informe Agropecuário, 128: 3-18.

SHARPLEY, A.N. 1989. Relationship between soil potassium forms and mineralogy. Soil Science Society of American Journal, 52: 1023-1028.

SHERRY, H.S. 1979. Ion exchange properties of the natural zeolite erionite. Clays \& Clay Minerals, 27: 231-237.
SHINZATO, M.C.; HYPOLITO, R.; VALARELLI, J.V. 1999. Utilização de vermiculita na retenção de íons metálicos. Anais da Academia Brasileira de Ciências, 71(3-I): 399-407.

SILVEIRA, M.L.A.; ALLEONI, L.R.F. 2003. Copper Adsorption in Tropical Oxisols. Brazilian Archives of Biology and Technology, 46(4): 529-536.

SKINNER, B.J. 1996. Recursos minerais da Terra. Edgard Blucher, São Paulo, 139 p.

SPARKS, D.L. 1987. Potassium dynamics in soils. In: B.A. Stewart (ed.) Advances in soil sciences. New York, Springer-Verlag, 6: 1-63.

SPARKS, D.L. 1995. Kinetics of metals sorption reactions. In: H.E. Allen, C.P. Huang, G.W. Bailey, A.R. Bowers (eds.) Metal speciation and contamination of soil. Boca Raton, FL, Lewis Publishers, p. 135-191.

WERLE, R.; GARCIA, R.A.; ROSOLEM, C.A. 2008. Lixiviação de potássio em função da textura e da disponibilidade do nutriente no solo. Revista Brasileira de Ciência do Solo, 32: 2297-2305.

WU, L.F. 2013. Uso de zeólitas na remoção de amônio de efluentes da indústria de reciclagem de alumínio. Universidade Federal de São Paulo, Diadema, Dissertação de Mestrado, 99 p.

\section{Endereço dos autores:}

Luis Fernando Wu, Mirian Chieko Shinzato, José Guilherme Franchi, Vanessa da Silva Andrade - Instituto de Ciências Ambientais, Químicas e Farmacêuticas da Universidade Federal de São Paulo, Rua São Nicolau, 210, CEP: 09913-030, Diadema, SP.E-mails: luiswu75@hotmail.com; mirian.chieko@unifesp. br; jfranchi@unifesp.br; v.andrade23@gmail.com

Sandra Andrade - Instituto de Geociências, Universidade de São Paulo, Caixa Postal 11348, CEP 05508080, São Paulo, SP. E-mail: sandrade@usp.br 
